\title{
Neutral Red Mediated Reductive Decolorization of Metal Complex Azo Dye by Shewanella Oneidensis MR-1
}

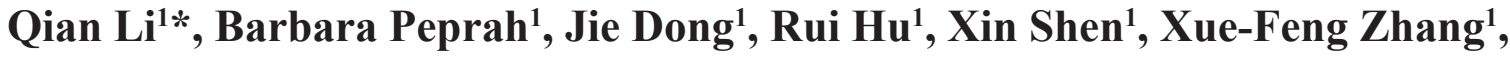 \\ Zhao-Ying Liu', Xiao-Ping Jiang ${ }^{2 *}$ \\ ${ }^{1}$ School of Environment and Safety Engineering, Jiangsu University, Zhenjiang, 212013, China \\ ${ }^{2}$ National Engineering and Technology Center for Information Agriculture, Nanjing Agricultural University, \\ Nanjing 210095, China
}

Received: 4 August 2020

Accepted: 26 February 2021

\begin{abstract}
Compared with ordinary azo dye pollutants, metal complex azo dyes are usually more recalcitrant and have more serious harm to our environment. This study focused on biodecolorization of acid blue 193 (AB 193), a typical metal complex azo dye, by Shewanella oneidnesis MR-1 (MR-1) under anaerobic conditions with neutral red (NR) as electron shuttle. The results indicated that effective biodecolorization of AB 193 by MR-1 was dependent on the presence of NR as electron shuttle. At presence of 1-5 $\mu \mathrm{M}$ NR, MR-1 could successfully decolorize AB 193, but hardly decolorized it without NR added. NR was found to be able to significantly improve decolorization capacity of MR-1 by accelerating electron transfer between dyes and cells. And the optimal biodecolorization parameters gotten by response surface methodology (RSM) were temperature $30.1^{\circ} \mathrm{C}, \mathrm{pH} 7.0,52.7 \mathrm{mg} / \mathrm{L}$ of initial $\mathrm{AB} 193$ concentration and $3.5 \mu \mathrm{M}$ of NR dosage, respectively to achieve maximum AB 193 decolorization (95.98\%) after $144 \mathrm{~h}$. Furthermore, the phytotoxicity of AB 193 to rice was significantly reduced during the decolorization process.
\end{abstract}

Keywords: acid blue 193, anaerobic biodecolorization, electron shuttle, Shewanella oneidnesis MR-1, response surface methodology

\section{Introduction}

In recent times, one major concern of scientists and environmentalists has been the discharge of untreated synthetic dyes such as azo dyes from textile and

*e-mail: xpjiang@njau.edu.cn

**e-mail: liq@ujs.edu.cn; liqian07@sina.com other manufacturing companies into the environment, which have proven to be difficult to degrade $[1,2]$. Dye effluents discharged into the environment can cause extreme environmental problems such as bad aesthetic appearance and opacity of water bodies as well as a possible poisonous threat to the ecosystem [3]. Therefore, treatment of azo dye-containing wastewater has emerged as a major environmental issue for an extended time. Whereas different physico- 
chemical methods can be applied to remove azo dyes from wastewater, their application is limited by several difficulties including expensive cost, complicated operation and possible secondary pollution problem [4]. Biological process has been established to be most effective due to its low cost and environmental friendliness [5]. In recent years, Shewanella, a typical exoelectrogenic bacterium (EEB), has been extensively used to biodecolorize some synthetic dyes such as methyl orange [6] and amaranth [7] because of its non-specific reduction degradation feature to environmental pollutants. However, information about biodecolorization of $\mathrm{AB}$ 193, a typical metal complex azo dye, is rather scarce due to its complex molecular structure containing heavy metal chromium $(\mathrm{Cr})$, biazo bonds and aromatic rings (Fig. S1), which result in more refractory biodegradability and have more serious environmental and ecological risks than other normal azo dyes. Up to now, it is unclear whether AB 193 can be decolorized by Shewanella. Therefore, this study carried out anaerobic decolorization of AB 193 using Shewanella, but our preliminary observation showed that $S$. oneidensis MR-1 could hardly decolorize it. However, it has been reported that electron shuttle could enhance Shewanella's biological decolorization capability to azo dyes [8], but the enhanced decolorization of metal complex azo dye by EEB has been rarely reported. Thence, if an appropriate electron shuttle is added into the decolorization system, could Shewanella effectively decolorize AB 193? In order to answer this question, it is imperative to understand how electron shuttle works.

Electron shuttle hypothesis based on redox mediators (RMs) is a usually justifiable basic for undefined azo dye anaerobic bio-reduction (ADAB) [9]. Electron shuttles possess abilities to act as RMs in numerous redox reactions, aid in conveying electrons between azo dyes and cells and ensue in the acceleration of the decolorization procedure [10]. Thionine, catechol, phenazine, aminophenols, and benzyl viologen are the compounds mostly reported to be able to serve as electron shuttle during redox (bio) transformation of pollutants [11]. They are capable of enhancing anaerobic bio-decolorization rate up to 2-10 times [10], but most of them are expensive, and their utilization in water purification may cause secondary pollution. NR is a redox dye (Fig. S2) and has all general properties of an ideal electron mediator $[12,13]$. Park and Zeikus found that NR was prior to other electron mediators used in microbial fuel cell (MFC) and also verified NR as an effective electron mediator for electricity production by E. coli in MFC [14]. However, the role and accelerating mechanism of NR, as a typical non-quinone RM, in dye degradation are still not fully understood. Especially, reports about the effect of NR on biodecolorization of metal complex azo dye by Shewanella are scarce.

Therefore, in this study, reductive decolorization of a metal complex azo dye, AB 193 by Shewanella with NR as electron shuttle was investigated. For this purpose, Shewanella oneidensis MR-1, a model strain, was used in decolorization of AB 193. Response surface methodology (RSM) was applied to optimize important factors (NR dose, initial AB 193 dye concentration, temperature and $\mathrm{pH}$ ) for the decolorization process and identify potential interactions between the factors in an ADAB system with RM added. S. oneidensis MR-1 mutants ( $\triangle m t r C / o m c A, \Delta m t r A, \Delta m t r B$, and $\triangle c y m A)$ were utilized in exploring the accelerating mechanism of NR to biodecolorization of metal complex azo dye. Furthermore, phytotoxicity of $A B$ 193 after decolorized was evaluated. As a novel finding, NR was proven as a high-efficiency electron shuttle to significantly speed up the decolorization process of metal complex azo dye by Shewanella. This study will provide further understanding on promotion effects of electron shuttle, especially non-quinone RM on azo dye biodecolorization and help to develop applications of EEB in the biodegradation field of refractory pollutants.

\section{Materials and Methods}

\section{Bacterial Strains and Culture Conditions}

The wild type of $S$. oneidensis MR-1 and it's metal respiratory (Mtr) mutants ( $\triangle m t r C / o m c A, \Delta m t r A, \Delta m t r B$ and $\triangle \operatorname{cym} A)$ used in this study were kindly provided by Prof. K. H. Nealson from the University of Southern California and grown in Luria-Bertani (LB) medium at $30^{\circ} \mathrm{C}$ and $200 \mathrm{rpm}$ shaking till the late stationary phase. Then the cells were accumulated by centrifugation at $6000 \mathrm{rpm}$ for $5 \mathrm{~min}$, washed twice with the defined culture medium (DCM) and suspended in this medium for the decolorization experiments. The used DCM contained $4.3 \mathrm{mM} \mathrm{NaH} \mathrm{PO}_{4}, 28 \mathrm{mM} \mathrm{NH} \mathrm{Cl}_{4}, 7.5 \mathrm{mM}$ $\mathrm{NaOH}, 1.3 \mathrm{mM} \mathrm{KCl}, 100 \mathrm{mM} \mathrm{NaCl}$, and $10 \mathrm{~mL} / \mathrm{L}$ each of amino acid solution, vitamin solution and trace mineral stock solution [15]. Lactate $(18 \mathrm{mM})$ was added as the only carbon source. The medium was buffered at pH 7.0 with $50 \mathrm{mM}$ 4-(2-hydroxyerhyl) piperazine-1erhanesulfonic acid, unless otherwise mentioned.

\section{AB 193 Biodecolorization Treatments}

$100 \mathrm{~mL}$ serum vials were used for the anaerobic decolorization experiments. $50 \mathrm{~mL}$ of the DCM with bacterial cells $\left(4 \sim 6 \times 10^{6} \mathrm{CFU} / \mathrm{mL}\right)$, AB $193(50 \mathrm{mg} / \mathrm{L}$, unless otherwise stated) and NR $(4 \mu \mathrm{M}$, unless otherwise stated) was put into each serum vial. AB 193 was used as an electron acceptor and NR as an electron shuttle. The treatment without NR added was set as the control. Then all serum vials were bubbled with $\mathrm{N}_{2}$ for 15 min to get rid of $\mathrm{O}_{2}$, subsequently sealed with butyl rubber stoppers and put into an incubator that shook at $200 \mathrm{rpm}, 30^{\circ} \mathrm{C}$ (unless otherwise mentioned). Every experiment was performed in triplicate.

Decolorization efficiency of AB 193 was monitored at $575 \mathrm{~nm}$ using a UV-VIS spectrophotometer (Mapada 
UV-1200, Shanghai, China). The decolorization percentage was calculated as follows [16]:

$$
\% \text { Decolorization }=\frac{A_{0}-A_{t}}{A_{0}} \times 100
$$

...where $A_{0}$ and $A_{t}$ are absorbance values of the initial solution and the observed sample at time t, respectively.

\section{NR Reoxidation Assay}

The reduction and reoxidation of NR as the electron shuttle in AB 193 decolorization were explored using $100 \mathrm{~mL}$ serum vials with $4 \mu \mathrm{M} \mathrm{NR}$ and $S$. oneidensis MR-1 cells $\left(4 \sim 6 \times 10^{6} \mathrm{CFU} / \mathrm{mL}\right)$. At first, the vials were anaerobically incubated for $72 \mathrm{~h}$ and NR was reduced by $S$. oneidensis MR-1. Then the mixed liquid in the vials was sterilized by filtration using $0.22 \mu \mathrm{m}$ mesh. The filtrate was mixed with the dye solution containing $50 \mathrm{mg} / \mathrm{L} \mathrm{AB} 193$ at a volume ratio of 1 [17]. The absorbance value at $533 \mathrm{~nm}$ was measured using a UV-VIS spectrophotometer (Mapada UV-1200, Shanghai, China) to observe the reduction or reoxidation of NR.

\section{RSM Optimization Experiment}

In order to optimize $\mathrm{AB} 193$ biodecolorization effect, obtain the optimal decolorization parameters and study the interaction between them, RSM based on Box-Behnken design (BBD) was used. Four vital decolorization factors, namely incubation temperature (A), medium $\mathrm{pH}$ (B), initial AB 193 concentration (C) and NR dosage (D), were selected in this study. All factors were investigated at three similarly spaced levels coded as $-1,0$ and +1 . The response was ascertained as the \% decolorization of AB 193. Design-Expert software (Version 10, Stat-Ease Inc.) was used to investigate the received results. The range of parameter values (Table 1) used was based on the initial observation for effective decolorization. To investigate the variable response and predict the most appropriate point utilizing statistical analysis, the following quadratic polynomial equation was used to fit the experimental results.

$$
\begin{aligned}
Y= & \beta_{0}+\sum_{i=1}^{3} \beta_{i} x_{i}+\sum_{i=1}^{3} \beta_{i i} x_{i}^{2} \\
& +\sum_{i=1}^{3} \sum_{\mathrm{j}=\mathrm{i}+1}^{4} \beta_{i j} x_{i} x_{j}+e
\end{aligned}
$$

...where $Y$ is the selected response ( $\%$ decolorization); $\beta_{0}$ is the constant; $\beta_{i}, \beta_{i i}$ and $\beta_{i j}$ are the regression coefficients of variables $x_{1}(A), x_{2}(B), x_{3}(C)$, and $x_{4}(D)$, for linear, quadratic, and interactive outcomes, respectively; $e$ refers to the residual term [18].

The design developed led to 29 experimental runs, along with 24 trials and 5-center points. Regression analysis was performed on the results. The statistical significance of the regression models was tested by analysis of variance (ANOVA). And 3D response surfaces was used to explain the synergistic effect of variables on the \% decolorization of $\mathrm{AB} 193$.

\section{Phytotoxicity Evaluation}

To evaluate the toxicity of AB 193 and its decolorization metabolites, phytotoxicity assay was performed using rice seeds since rice was one of the most important food crops regularly used for phytotoxicity analysis [19]. After sterilization via filtration to get rid of any cells, AB $193(52.7 \mathrm{mg} / \mathrm{L})$ and its decolorized solution were used to treat the rice seeds, respectively. The defined culture medium without dye served as the control. All prepared solutions were diluted twice with distilled water to avoid osmotic stress caused by the medium. The sterile transparent bottle with diameter of $90 \mathrm{~mm}$, which was lined with a sterile filter paper for the proper steady distribution of solution, was used as a basis. After sterilized by $0.9 \% \mathrm{NaClO}$ solution, the rice seeds were positioned on the filter paper and sprayed by $5 \mathrm{~mL}$ each of the aforementioned solutions on the first day and then $2 \mathrm{~mL}$ per day. After 10 days, the lengths of shoot and root were recorded. Each treatment had three replicates. One way analysis of variance (ANOVA) with Tukey-Kramer multiple comparisons test was applied to analyse the data.

Table 1. Experimental values and levels of independent variables.

\begin{tabular}{|c|c|c|c|c|}
\hline \multirow{2}{*}{ Independent variables } & \multirow{2}{*}{ Symbols } & \multicolumn{3}{|c|}{ Coded and actual levels (Range) } \\
\cline { 3 - 5 } & & Low $(-1)$ & Middle $(0)$ & High $(+1)$ \\
\hline Incubation temperature $\left({ }^{\circ} \mathrm{C}\right)$ & $\mathrm{A}$ & 25 & 75 & 45 \\
\hline $\mathrm{pH}$ of medium & $\mathrm{B}$ & 6 & 75 & 8 \\
\hline Initial $\mathrm{AB} 193$ concentration $(\mathrm{mg} / \mathrm{L})$ & $\mathrm{C}$ & 50 & 4.5 & 8 \\
\hline $\mathrm{NR}$ dose $(\mu \mathrm{M})$ & $\mathrm{D}$ & 1 & & 700 \\
\hline
\end{tabular}



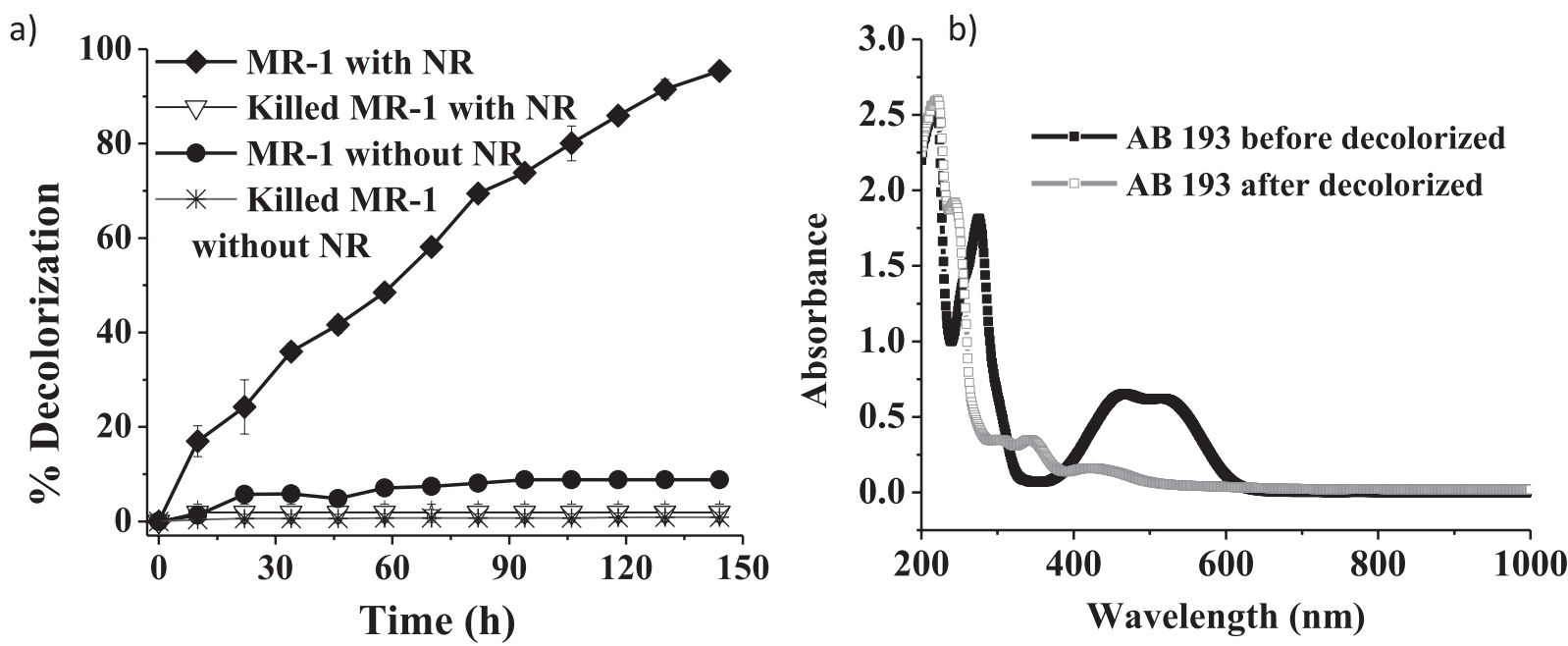

Fig. 1. AB 193 decolorization by MR-1 with or without NR a) The percentage of decolorization with time; b) UV-VIS spectra of AB 193 before and after 144-h decolorization with NR.

\section{Results and Discussion}

\author{
Anaerobic Decolorization of AB 193 \\ by $S$. oneidnesis MR-1
}

AB 193 decolorization by $S$. oneidensis MR-1 under anaerobic conditions in the presence or absence of NR as RM was investigated. As seen in Fig. 1a), after a 144-h incubation, $S$. oneidensis MR-1 hardly decolorized AB $193 \quad(\%$ decolorization was only 7.8) in the absence of NR, but almost completely decolorized it (\% decolorization was 95.4) when $3.5 \mu \mathrm{M}$ NR was added. Meanwhile, the heat-killed $S$. oneidensis MR-1 showed no obvious decolorization effect on AB 193 no matter whether NR was added or not, which demonstrated that color removal of $\mathrm{AB}$ 193 by $S$. oneidensis MR-1 was mainly resulted from biodegradation, rather than biosorption. Moreover, the UV-VIS absorption spectra (200-1000 nm) showed that the characteristic absorption peak of AB 193 at $575 \mathrm{~nm}$ disappeared after decolorization (Fig. 1b), which also indicated that decolorization of AB 193 by S. oneidensis MR-1 was attributed to biodegradation. Furthermore, the break of azo bond acting as chromophore [6] can explain the disappearance of absorption peak. All these results showed that biodecolorization of AB 193 by $S$. oneidensis MR-1 was successfully realized by using NR as electron shuttle. And to our knowledge, this is the first report about the anaerobic biodegradation of $\mathrm{AB}$ 193 dye by EEB.

\section{Role of NR in AB 193 Biodecolorization}

In order to prove whether NR acts as an electron mediator in the biodecolorization of AB 193, the reoxidation experiment of NR was carried out. As seen from Fig. 2, when $S$. oneidensis MR-1 cells were anaerobically incubated with $4 \mu \mathrm{M} \mathrm{NR}, \mathrm{OD}_{533}$ readings of NR gradually decreased with time, which indicated that NR was reduced by accepting the electrons from the cells. It can also be seen from Fig. 2 that between $12 \mathrm{~h}$ and $24 \mathrm{~h}, \mathrm{OD}_{533}$ dropped gently, which indicated a slow reduction process of NR in the early stage of electron acceptance. However, after $24 \mathrm{~h}, \mathrm{OD}_{533}$ decreased quickly to zero, which indicated NR was completely reduced within $72 \mathrm{~h}$. Then the sample was filtered to get reduced NR solution which was mixed with $50 \mathrm{mg} / \mathrm{L}$ AB 193 in equal volume. Subsequently, $\mathrm{OD}_{533}$ increased rapidly to the initial value after $10 \mathrm{~h}$, which indicated that NR was re-oxidized by AB 193 after $10 \mathrm{~h}$. The findings suggested that NR acted as an electron shuttle during AB 193 decolorization process by $S$. oneidensis MR-1.

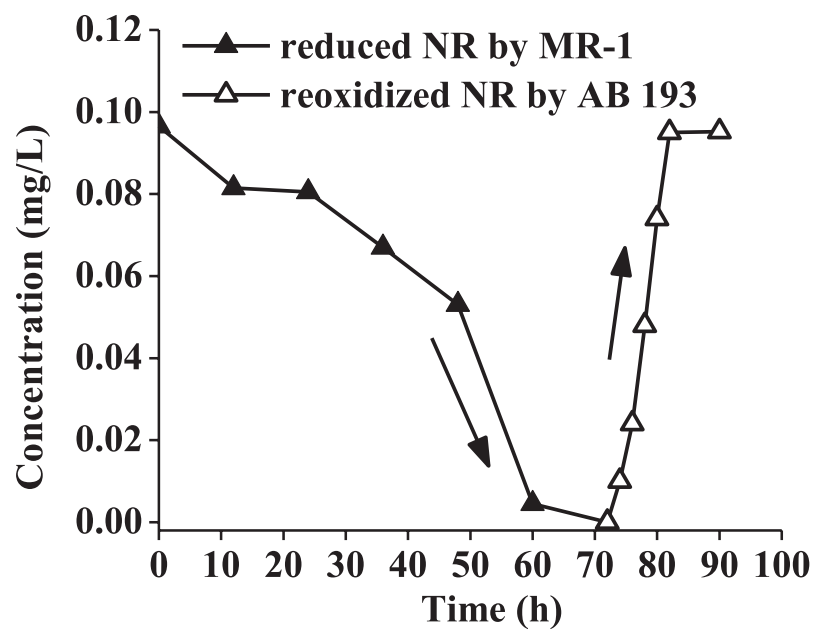

Fig. 2. The reduction or reoxidation of NR by MR-1 or AB 193. The arrows indicate the reduction or reoxidation pathway of NR. 
Table 2. BBD matrix showing actual and predicted values of AB 193 decolorization (\%).

\begin{tabular}{|c|c|c|c|c|c|c|}
\hline \multirow{2}{*}{ Run } & \multirow{2}{*}{$\begin{array}{l}\text { Incubation temperature } \\
\qquad\left({ }^{\circ} \mathrm{C}\right)\end{array}$} & \multirow{2}{*}{$\begin{array}{l}\text { Medium } \\
\text { pH }\end{array}$} & \multirow{2}{*}{$\begin{array}{c}\text { Initial AB } 193 \text { concentration } \\
(\mathrm{mg} / \mathrm{L})\end{array}$} & \multirow{2}{*}{$\begin{array}{l}\text { NR dosage } \\
\qquad(\mu \mathrm{M})\end{array}$} & \multicolumn{2}{|c|}{ \%Decolorization } \\
\hline & & & & & Experimental & Predicted \\
\hline 1 & 45 & 6 & 75 & 4.5 & 32.42 & 38.71 \\
\hline 2 & 35 & 7 & 75 & 4.5 & 74.62 & 83.81 \\
\hline 3 & 35 & 7 & 75 & 4.5 & 83.99 & 83.81 \\
\hline 4 & 25 & 7 & 100 & 4.5 & 86.39 & 84.95 \\
\hline 5 & 45 & 7 & 75 & 1 & 43.38 & 36.18 \\
\hline 6 & 25 & 7 & 50 & 4.5 & 96.05 & 98.51 \\
\hline 7 & 25 & 7 & 75 & 8 & 94.10 & 94.26 \\
\hline 8 & 35 & 6 & 100 & 4.5 & 71.55 & 77.03 \\
\hline 9 & 35 & 7 & 100 & 1 & 57.68 & 65.61 \\
\hline 10 & 45 & 8 & 75 & 4.5 & 35.64 & 38.71 \\
\hline 11 & 35 & 8 & 75 & 1 & 72.66 & 81.29 \\
\hline 12 & 35 & 7 & 75 & 4.5 & 85.88 & 83.81 \\
\hline 13 & 45 & 7 & 75 & 8 & 53.64 & 41.24 \\
\hline 14 & 35 & 7 & 75 & 4.5 & 89.40 & 83.81 \\
\hline 15 & 35 & 7 & 50 & 1 & 94.14 & 96.96 \\
\hline 16 & 35 & 6 & 75 & 8 & 86.85 & 86.34 \\
\hline 17 & 35 & 8 & 100 & 4.5 & 88.59 & 77.03 \\
\hline 18 & 45 & 7 & 100 & 4.5 & 27.88 & 31.92 \\
\hline 19 & 35 & 7 & 50 & 8 & 82.92 & 84.24 \\
\hline 20 & 35 & 6 & 75 & 1 & 94.75 & 81.29 \\
\hline 21 & 25 & 7 & 75 & 1 & 86.91 & 89.20 \\
\hline 22 & 45 & 7 & 50 & 4.5 & 39.30 & 45.49 \\
\hline 23 & 35 & 8 & 75 & 8 & 80.34 & 86.34 \\
\hline 24 & 25 & 8 & 75 & 4.5 & 89.91 & 91.73 \\
\hline 25 & 35 & 8 & 50 & 4.5 & 94.39 & 90.60 \\
\hline 26 & 35 & 7 & 100 & 8 & 82.01 & 88.45 \\
\hline 27 & 35 & 7 & 75 & 4.5 & 96.38 & 83.81 \\
\hline 28 & 25 & 6 & 75 & 4.5 & 97.03 & 91.73 \\
\hline 29 & 35 & 6 & 50 & 4.5 & 88.70 & 90.60 \\
\hline
\end{tabular}

\section{Optimization of AB 193 Decolorization Using RSM}

Decolorization conditions such as medium $\mathrm{pH}$, culture temperature, initial AB 193 dye concentration and electron mediator dosage were shown in preliminary tests to have important effects on AB 193 decolorization by $S$. oneidensis MR-1 mediated by NR. Based on the preliminary observations, RSM was applied to optimize effects of the above mentioned four parameters on $\mathrm{AB}$ 193 decolorization and get the optimal experiment conditions so that the maximum decolorization of $\mathrm{AB}$ 193 could be obtained.

\section{Development of Regression and Model Equation}

The actual and predicted values of 29 experiments designed by BBD were shown in Table 2. As seen from Table 2, all low decolorization values $(<50 \%)$ were observed at $45^{\circ} \mathrm{C}$, while below $45^{\circ} \mathrm{C}, \%$ decolorization was high $(>50 \%)$ and varied with medium $\mathrm{pH}$, initial AB 193 concentration and NR dosage. It suggested that 
Table 3. ANOVA for reduced quadratic model of decolorization efficiency.

\begin{tabular}{|c|c|c|c|c|c|c|}
\hline Source & $\begin{array}{c}\text { Sum of } \\
\text { squares }\end{array}$ & $\begin{array}{c}\text { Degree of } \\
\text { freedom }\end{array}$ & $\begin{array}{c}\text { Mean } \\
\text { Square }\end{array}$ & F-Value & $\begin{array}{c}\text { p-value } \\
\text { Prob }>\text { F }\end{array}$ & Remarks \\
\hline Model & 11810.76 & 5 & 2362.15 & 44.54 & $<0.0001$ & Significant \\
\hline A (incubation temperature) & 8433.89 & 1 & 8433.89 & 159.03 & $<0.0001$ & \\
\hline C (initial AB 193 concentration) & 552.16 & 1 & 552.16 & 10.41 & 0.0037 & \\
\hline D (NR dosage) & 76.71 & 1 & 76.71 & 1.45 & 0.2413 & \\
\hline CD & 315.95 & 1 & 315.95 & 5.96 & 0.0228 & \\
\hline $\mathrm{A}^{2}$ & 2432.05 & 1 & 2432.05 & 45.86 & $<0.0001$ & \\
\hline Residual & 1219.78 & 23 & 53.03 & & & \\
\hline Lack of Fit & 966.93 & 19 & 50.89 & 0.81 & 0.6732 & Not significant \\
\hline Pure Error & 252.85 & 4 & 63.21 & & & \\
\hline Cor Total & 13030.54 & 28 & & & & \\
\hline
\end{tabular}

$\mathrm{R}^{2}=0.9064$, Adj- $\mathrm{R}^{2}=0.8860$

temperature at around $30^{\circ} \mathrm{C}$ was favorable for growth and activity of microbial cell, which eventually influenced the decolorization process of AB 193. Furthermore, the $\%$ decolorization varied between 27.88 and $97.03 \%$ suggested condition levels and their interactions extensively influenced the decolorization process.

As shown in Table S1, for the response (\% decolorization) examined, the quadratic polynomial model was selected to be used for further analysis. However, model summary statistics showed that the maximum Adj- $\mathrm{R}^{2}$ value (0.84) was not close to the Pre- $\mathrm{R}^{2}$ value $(0.63)$ as normally expected since the difference between them was more than 0.2 , which indicated model inadequacy. Thus, deletion by a backward elimination process to improve model adequacy was applied [20]. ANOVA results (Table 3) showed the reduced quadratic model had three linear significant terms (A, C, D), one interaction (CD) and one quadratic term $\left(\mathrm{A}^{2}\right)$, and thus included within the final quadratic design to conserve model hierarchy [21]. The p-value was less than 0.05 , which indicated that the modified quadratic model was statistically significant. And the lack-of-fit value was 0.81 and indicated nonsignificance as desired, thus it could be applied for further studies [22]. The determined $\mathrm{R}^{2}$ and $\mathrm{Adj}-\mathrm{R}^{2}$ for decolorization efficiency were 0.9064 and 0.8860 , respectively, which showed that the equation was reliable. The final reduced model equation for AB 193 biodecolorization mediated by NR was given as follows:

$$
\begin{gathered}
\% \text { decolorization }=83.81-26.51 A-6.78 C \\
+2.53 D+8.89(C \cdot D)-18.59 A^{2}
\end{gathered}
$$

\section{Effects of Interactive Factors on AB 193 Decolorization}

The three dimensional (3-D) response surface plots were shown in Fig. 3. This figure was used to determine effects of mutual interactions between variables temperature, $\mathrm{pH}$, initial $\mathrm{AB} 193$ concentration and NR dosage on \% decolorization of AB 193. The 3 -D response surface plots suggested the impact of two variables within their studied limits, with the alternative variables fixed to zero level. The nature and extent of interaction between two independent variables were predicted from the shape of contour plots [23].

Fig. 3a) showed the interactive effect of temperature and initial AB 193 dye concentration on \% decolorization of $\mathrm{AB} 193$. As seen from the figure, when temperature and initial dye concentration range were $25-40^{\circ} \mathrm{C}$ and $70-80 \mathrm{mg} / \mathrm{L}$, respectively, \% decolorization increased with the increase of temperature and initial dye concentration, but decreased with the further increase of them. Since $S$. oneidensis MR-1 is a kind of mesophilic bacteria [24], it could efficiently decolorize AB 193 at not too high temperatures. Similarly, Shewanella decolorationis LDS1 was reported to be able to grow well and effectively reduce toxic compounds such as chromate at the temperature range of 24 to $40^{\circ} \mathrm{C}$ [25]. Guo and Zhou also reported that the isolated bacteria grew best at moderate temperature $\left(20-45^{\circ} \mathrm{C}\right)$ and could effectively decolorize five azo dyes within $24 \mathrm{~h}$ [26]. As for the increasing initial AB 193 concentrations, the decrease of $\%$ decolorization might be explained by toxic stresses generated from high dye concentration [16]. It also implied that AB 193 could cause harm to $S$. oneidensis MR-1 cells at high concentration.

Fig. 3b) showed the interactive effect of temperature and medium $\mathrm{pH}$ on $\%$ decolorization of $\mathrm{AB} 193$. As seen from the figure, $\%$ decolorization at a certain temperature was independent of the change of medium $\mathrm{pH}$. For instance, within a $\mathrm{pH}$ range of $6-8$, $\%$ decolorization at $31.5^{\circ} \mathrm{C}$ was a constant value of $90 \%$. However, when the medium $\mathrm{pH}$ was constant, the $\%$ decolorization decreased with increasing temperature. The increase in both medium $\mathrm{pH}$ and temperature showed a negative correlation and resulted 
in lower decolorization efficiency. The similar result was also reported on influence of $\mathrm{pH}$ change on the decolorization of X-GRL by $S$. oneidensis MR-1 [16].

Fig. 3c) showed the interaction effect of temperature and NR dosage on AB 193 decolorization. As seen from the figure, the maximum decolorization efficiency $(90 \%)$ was attained at $\mathrm{NR}$ dosage range of $1-8 \mu \mathrm{M}$ and temperature of $25^{\circ} \mathrm{C}-30^{\circ} \mathrm{C}$. However, a gradual decrease in $\%$ decolorization with increasing NR dosage was observed when temperature exceeded $30^{\circ} \mathrm{C}$. It was a similar effect as shown in Fig. 3a) and Fig. 3b). Furthermore, Fig. 3c) also distinctly showed the combined effects of these parameters so that their running effects at their specified levels to increase AB 193 decolorization were to be considered.

Fig. 3d) showed the interactive effect of NR dosage and initial AB 193 concentration on \% decolorization of $A B$ 193. As seen from the figure, when NR dosage and initial dye concentration were both at a relatively low level, \% decolorization was relatively high. When initial AB 193 dye concentration was low, increasing NR dosage $(1-8 \mu \mathrm{M})$ caused slight decrease of $\%$ decolorization by about $8 \%$. Instead, at high initial dye concentration, increasing NR dosage (1-8 $\mu \mathrm{M})$ significantly increased the $\%$ decolorization. This indicated that for effective decolorization $(>90 \%)$ of AB 193 with dye concentration of $50-100 \mathrm{mg} / \mathrm{L}$, NR dosage should be increased accordingly from 1-8 $\mu \mathrm{M}$. It indicated that NR could efficiently mediate electron transfer between electron donor (Lactate) and electron acceptor (dye) and behaved like a bridge between them [27], which caused the increase of AB 193 decolorization.

In conclusion, Fig. 3 generally showed that it was necessary to increase the concentration of electron mediator NR while increasing the initial AB 193 concentration so as to ensure the decolorization efficiency of AB 193, and that temperature was the most
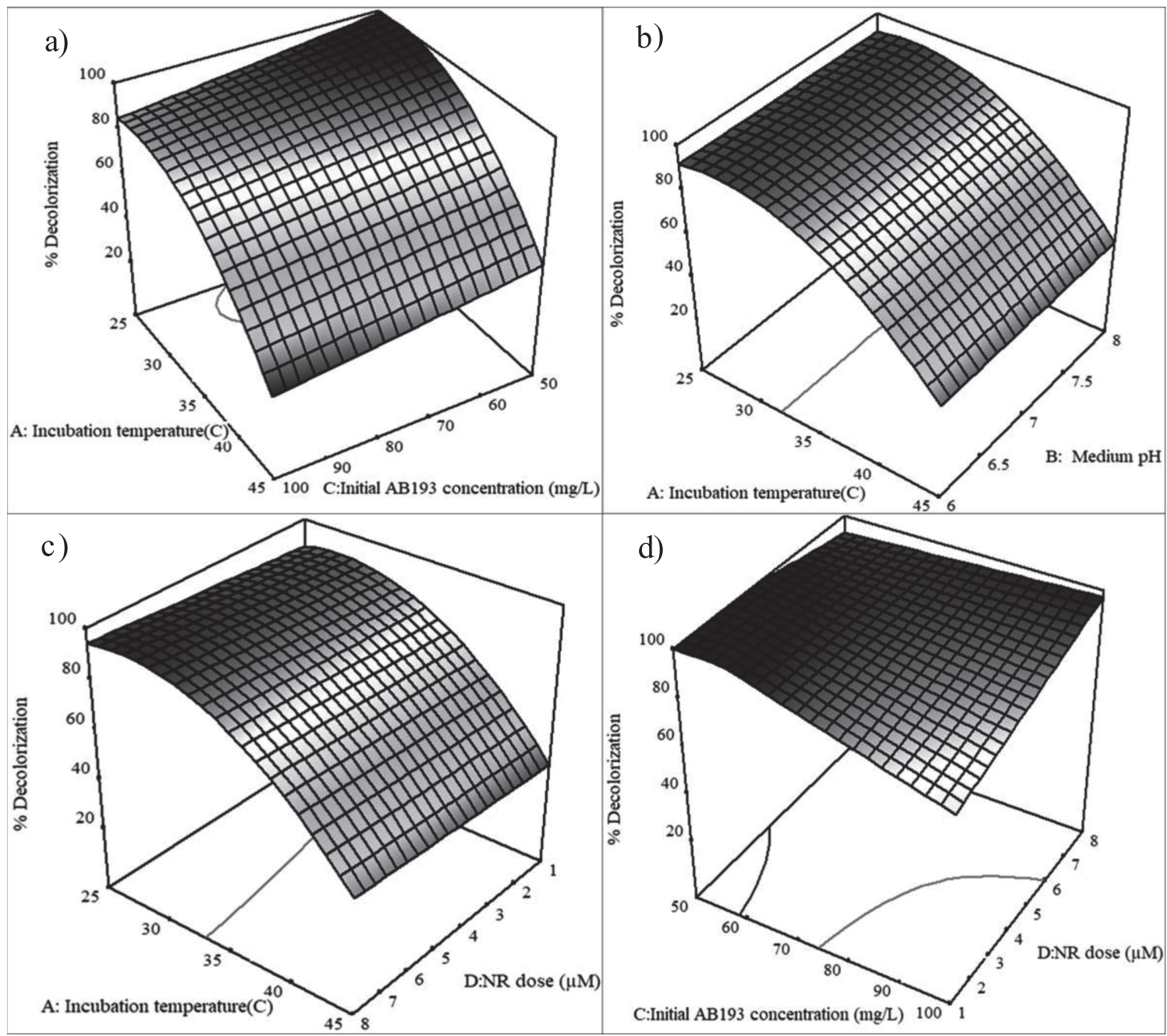

Fig. 3. Three-dimensional response surface plots showing effects of mutual interaction of different variables on \%decolorization of AB 193 by $S$. oneidensis MR-1 with NR as a mediator. a) The response plot of temperature vs initial AB 193 concentration on \%decolorization when keeping $\mathrm{pH} 7.5$ and NR dosage $4.5 \mu \mathrm{M}$. b) The response plot of temperature vs $\mathrm{pH}$ on \%decolorization when keeping the initial AB 193 concentration $75 \mathrm{mg} / \mathrm{L}$ and NR dosage $4.5 \mu \mathrm{M}$. c) The response plot of temperature vs NR dosage on \%decolorization when keeping pH 7.5 and initial AB 193 concentration constant $75 \mathrm{mg} / \mathrm{L}$. d) The response plot of NR dosage vs initial AB 193 concentration on \%decolorization when keeping $\mathrm{pH} 7.5$ and temperature $27.7^{\circ} \mathrm{C}$. 
important factor affecting the decolorization efficiency of AB 193, but $\mathrm{pH}$ had little effect.

\section{Optimal Decolorization Conditions}

Design-Expert software was employed to identify the optimal decolorization parameters to obtain the highest \% decolorization of AB 193. Then verification experiments were performed under the predicted optimal conditions so as to test the validity and adequacy of the prediction model. The conditions under which the predicted AB 193 decolorization rate obtained by the software was over $95 \%$ could be selected as the optimal candidate. Thus five groups of conditions with \% decolorization more than $96 \%$ (Table S2) from the predicted results were selected for the validation experiments to determine the optimal one. As seen from Table S2, considering both the predicted and experimental values of AB 193 decolorization rate, the optimal decolorization conditions were determined as: initial AB 193 concentration of $52.7 \mathrm{mg} / \mathrm{L}$, NR dosage of $3.5 \mu \mathrm{M}$, incubation temperature of $30.1^{\circ} \mathrm{C}$ and $\mathrm{pH}$ 7.0. That is, the predicted and experimental values of $\%$ decolorization under these conditions were both the highest, which were $99.9 \%$ and $95.9 \%$, respectively.

\section{Relationship between Mtr Pathway of $S$. oneidensis MR-1 and AB 193 Reduction Mediated by NR}

The metal respiratory (Mtr) pathway of $S$. oneidensis MR-1, which is comprised of a series of c-type cytochromes, such as $\triangle m t r A, \Delta m t r B, \Delta m t r C /$ omc $A$ and $\triangle c y m A$, is an essential transmembrane electron transfer channel [28], which provides a special reducibility to extracellular pollutants. Therefore, Mtr mutant experiments were carried out to verify whether Mtr pathway was also associated with the promotion of NR to AB 193 decolorization. As shown in Fig. 4,

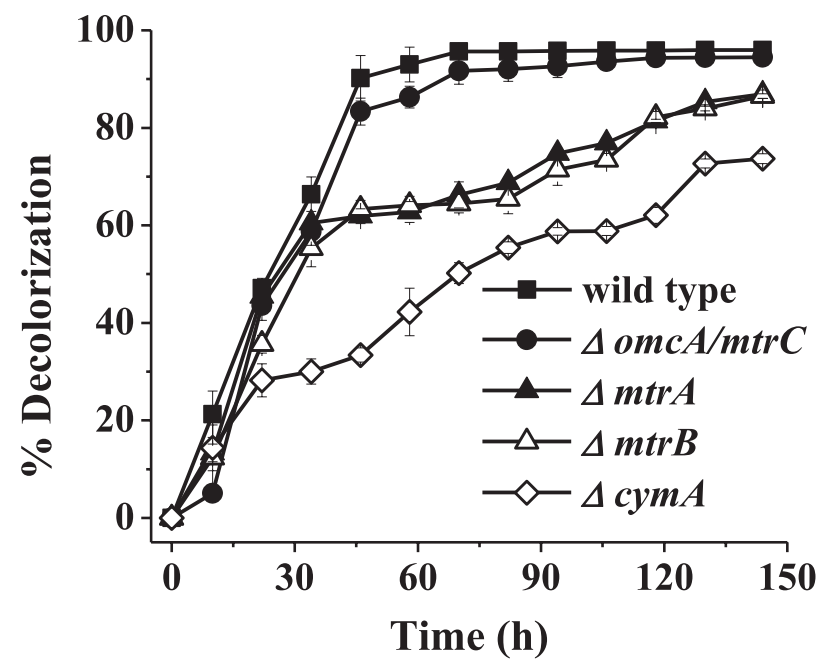

Fig. 4. Effects of $4 \mu \mathrm{M}$ NR on AB 193 decolorization by $S$. oneidensis MR-1 wild type and its mutants ( $\triangle m$ trA, $\triangle m$ trB $\triangle o m c A / m t r C$, and $\triangle c y m A)$. the \% decolorization of AB 193 by the wild type was the highest and reached $90.1 \%$ with 50 -h incubation. However, it was unexpected that all the mutants still sustained an elevated decolorization activity after $50 \mathrm{~h}$. The decolorization rate for $\Delta m t r A, \Delta m t r B, \Delta o m c A / m t r C$ and $\triangle c y m A$ attained $86.9 \%, 86.5 \%, 94.5 \%$ and $73.7 \%$, respectively after 144 -h incubation. This suggested that the electron transfer to AB 193 mediated by NR was not only through the Mtr pathway. The blocking of $\triangle$ cymA was reported to encode a c-type cytochrome which played a key role in electron transfer from quinone pool to terminal electron acceptors [6], so in our study, the 144-h decolorization ability of $S$. oneidensis MR-1 to AB 193 decreased by about 25\% after $\Delta$ cymA protein was knocked out. However, after blocking of the $\Delta m t r C /$ omcA pathway by $144 \mathrm{~h}$, the decolorization ability of the strain was hardly affected, which also suggested that there might be other electron transport channels besides the Mtr pathway involved in NR mediated reductive decolorization of AB 193 by S. oneidensis MR-1.

With the above analysis, a possible reductive decolorization mechanism of AB 193 by S. oneidensis MR-1 mediated by NR was proposed in Fig. 5. The successful anaerobic decolorization of AB 193 by $S$. oneidensis MR-1 after adding NR might be attributed to the enhanced electron transfer between $S$. oneidensis MR-1 cells and AB 193 dye caused by NR as electron shuttle.

\section{Phytotoxicity Evaluation}

The metabolites of azo dyes are usually aromatic amines under anaerobic conditions, which have been reported to be carcinogenic and mutagenic to living organisms [29]. To evaluate the toxicity of metabolites of azo dyes, phytotoxicity test is commonly conducted on selected plant types by determining growth inhibition effect of the decolorized azo dye solution [19]. In this study, rice was selected as the plant type for the phytotoxicity evaluation. As shown in Fig. S3, when rice seeds were exposed in AB 193 solution, their growth was noticeably inhibited. The root and shoot lengths of the rice plant treated with $\mathrm{AB} 193$ solution were reduced by $25 \%$ and $35 \%$, respectively compared with the control (treatment with medium). However, the growth of rice seeds was not affected by AB 193 decolorized products, on the contrary, the lengths of root and shoot of the rice plant were increased by $18 \%$ and $12 \%$, respectively when compared with the control, which was in accordance with the result observed in the decolorization of congo red [8]. It showed that $S$. oneidensis MR-1 could successfully decrease the phytotoxicity of dyes during the decolorization process.

\section{Conclusions}

The reductive decolorization of metal complex azo dye AB 193 by S. oneidnesis MR-1 using NR as 


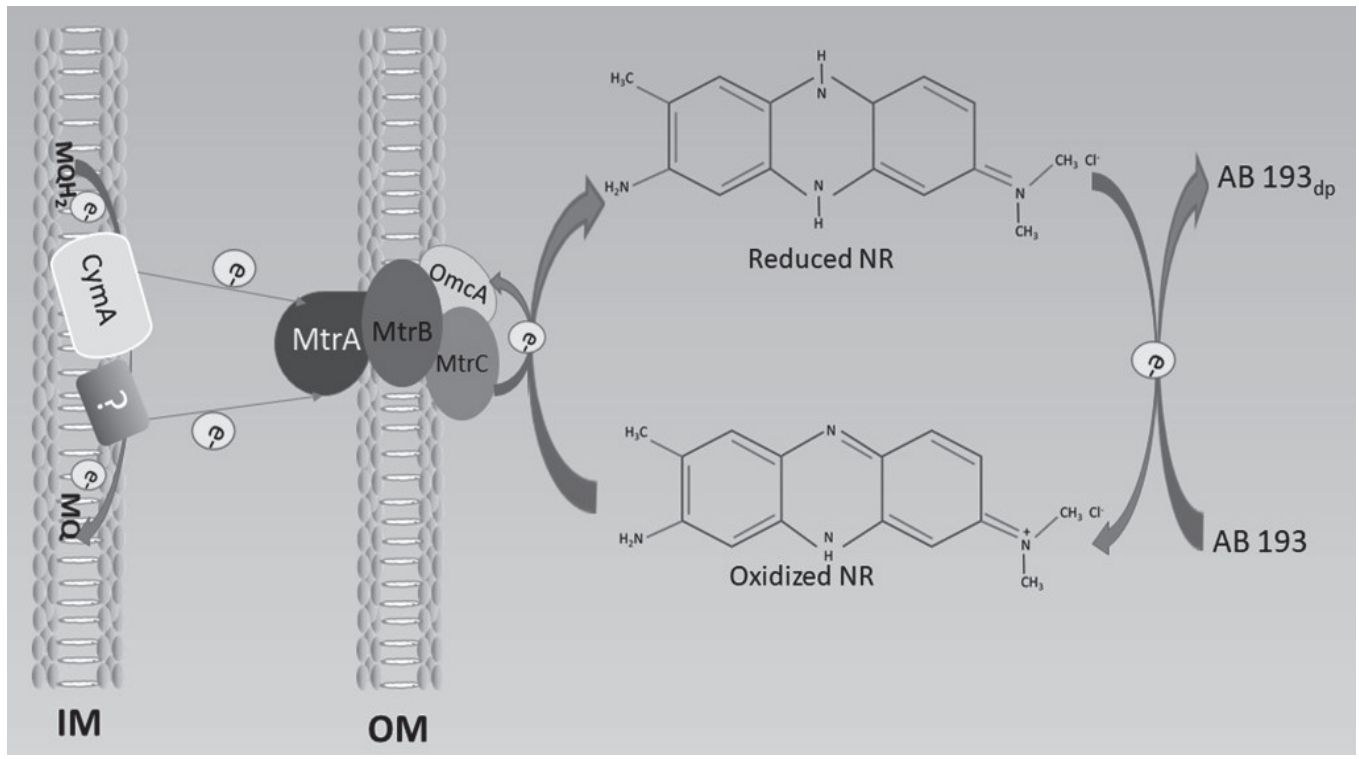

Fig. 5. Proposed anaerobic reduction mechanism of NR mediated AB 193 decolorization by S. oneidensis MR-1. OM: outer membrane; IM: inner membrane; AB $193_{\mathrm{dp}}$ : AB 193 degradation products.

electron shuttle was investigated. The refractory $A B$ 193 dye was for the first time successfully biodegraded by EEB. NR was found to play a key role during AB 193 biodecolorization by $S$. oneidnesis MR-1. Whether AB 193 could be effectively decolorized by $S$. oneidnesis MR-1 depended on the involvement of NR. And NR has been proved to act as an electron shuttle in AB 193 biodecolorization by S. oneidnesis MR-1. It was found that the mechanism of NR promoting the biodecolorization of $\mathrm{AB} 193$ was related to its acceleration of the electron transfer between dye and $S$. oneidnesis MR-1 cells. Furthermore, the NR mediated biodecolorization process of $\mathrm{AB} 193$ was optimized and the optimal decolorization parameters were obtained by using RSM. The phytotoxicity of AB 193 after decolorized by $S$. oneidnesis MR-1 was significantly reduced.

\section{Acknowledgements}

This study was partially supported by the National Natural Science Foundation of China (51478208), the Key Research and Development Projects of Modern Agriculture in Jiangsu Province (BE2017334), the Project Funded by the Priority Academic Program Development of Jiangsu Higher Education Institutions (PAPD) and the Jiangsu Collaborative Innovation Center of Technology and Material of Water Treatment.

\section{Conflicts of Interest}

The authors declare no conflict of interest.

\section{References}

1. YASEEN D.A., SCHOLZ M. Textile dye wastewater characteristics and constituents of synthetic effluents: a critical review. Int. J. Environ Sci.Technol. 16 (2), 1193, 2019.

2. JAMEE R., SIDDIQUE R. Biodegradation of Synthetic Dyes of Textile Effluent by Microorganisms: An Environmentally and Economically Sustainable Approach. Eur. J. Microbiol. Immunol. (Bp). 9 (4), 114, 2019.

3. CHAUDHARI A.U., TAPASE S.R., MARKAD V.L., KODAM K.M. Simultaneous decolorization of reactive Orange M2R dye and reduction of chromate by Lysinibacillus sp. KMK-A. J. Hazard. Mater. 262, 580, 2013.

4. NJIKI A., KAMGANG-YOUBI G., LAMINSI S., LONTSI C., PAYOM G., NOLA M., NGAMENI E. Gliding arc discharge-assisted biodegradation of crystal violet in solution with Aeromonas hydrophila strain. Int. J. Environ Sci.Technol. 13 (1), 263, 2016.

5. MEERBERGEN K., WILLEMS K.A., DEWIL R., VAN IMPE J., APPELS L., LIEVENS B. Isolation and screening of bacterial isolates from wastewater treatment plants to decolorize azo dyes. J. Biosci. Bioeng. 125 (4), 448, 2018.

6. CAI P.-J., XIAO X., HE Y.-R., LI W.-W., CHU J., WU C., HE M.-X., ZHANG Z., SHENG G.-P., LAM M.H.-W., XU F., YU H.-Q. Anaerobic biodecolorization mechanism of methyl orange by Shewanella oneidensis MR-1. Appl. Microbiol. Biotechnol. 93 (4), 1769, 2012.

7. FANG Y., LIU J., KONG G., LIU X., YANG Y., LI E., CHEN X., SONG D., YOU X., SUN G., GUO J., XU M. Adaptive Responses of Shewanella decolorationis to Toxic Organic Extracellular Electron Acceptor Azo Dyes in Anaerobic Respiration. Appl. Environ. Microbiol. 85 (16), 2019.

8. LIU W., LIU L., LIU C., HAO Y., YANG H., YUAN B., JIANG J. Methylene blue enhances the anaerobic decolorization and detoxication of azo dye by Shewanella onediensis MR-1. Biochem. Eng. J. 110, 115, 2016.

9. MENG X., LIU G., ZHOU J., FU Q.S. Effects of redox 
mediators on azo dye decolorization by Shewanella algae under saline conditions. Bioresour. Technol. 151, 63, 2014.

10. RAU J., KNACKMUSS H.-J., STOLZ A. Effects of different quinoid redox mediators on the anaerobic reduction of azo dyes by bacteria. Environ. Sci. Technol. 36 (7), 1497, 2002.

11. CHEN B.-Y., HSUEH C.-C. Deciphering electron shuttles for bioremediation and beyond. Am. J. Chem. Eng. 4 (5), 114, 2016

12. IM C.H., KIM C., SONG Y.E., OH S.-E., JEON B.-H., KIM J.R. Electrochemically enhanced microbial CO conversion to volatile fatty acids using neutral red as an electron mediator. Chemosphere. 191, 166, 2018.

13. YANG D., GUO J., LU C., SONG Y., LI H., CHEN Z., XIE Z. A quasi-homogeneous catalysis and electron transfer chain for biodecolorization of azo dye by immobilized phenazine redox mediator. Int. Biodeterior. Biodegradation. 126, 69, 2018.

14. PARK D.H., ZEIKUS J.G. Electricity generation in microbial fuel cells using neutral red as an electronophore. Appl. Environ. Microbiol. 66 (4), 1292, 2000.

15. BRETSCHGER O., OBRAZTSOVA A., STURM C.A., CHANG I.S., GORBY Y.A., REED S.B., CULLEY D.E., REARDON C.L., BARUA S., ROMINE M.F. Current production and metal oxide reduction by Shewanella oneidensis MR-1 wild type and mutants. Appl. Environ. Microbiol. 73 (21), 7003, 2007.

16. LI Q., FENG X.-L., LI T.-T., LU X.-R., LIU Q.-Y., HAN X., FENG Y.-J., LIU Z.-Y., ZHANG X.-J., XIAO X. Anaerobic decolorization and detoxification of cationic red X-GRL by Shewanella oneidensis MR-1. Environ. Technol. 39 (18), 2382, 2018.

17. LI Q., FENG X., LU X., LI T., HAN X., XIAO X., WU X., LIU Z., YANG M., FENG Y. Combined intraand extracellular reduction involved in the anaerobic biodecolorization of cationic azo dye by Shewanella oneidensis MR-1. Chemosphere. 211, 701, 2018.

18. BEZERRA M.A., SANTELLI R.E., OLIVEIRA E.P., VILLAR L.S., ESCALEIRA L.A. Response surface methodology (RSM) as a tool for optimization in analytical chemistry. Talanta. 76 (5), 965, 2008.

19. BALAPURE K., AGHERA P., BHATT N., MADAMWAR D. Community Synergism: Degradation of Triazine Dye Reactive Black 1 by Mixed Bacterial Cultures KND_PR under Microaerophilic and Aerobic Conditions. Environ. Process. 6 (3), 713, 2019.
20. DARABI-GOLESTAN F., HEZARKHANI A. Discrimination geochemical interaction effects on mineralization at the polymetallic Glojeh deposit, NW Iran by interative backward quadratic modeling. Acta Geochim. 39 (2), 236, 2020.

21. MONTGOMERY D.C., ANDERSON-COOK C.M. Response surface methodology: process and product optimization using designed experiments, Illustrated, Reprint ed., Vol. 705, Wiley Series in Probability and Statistics, John Wiley \& Sons, New York, 2009.

22. VINING G.G., KOWALSKI S. Statistical methods for engineers, 3rd Edition ed., Duxbury Press, California,USA, 2010.

23. ZHOU Q., DING L., ZHU Y., ZHONG M., YANG C. Process Parameters Optimization of Gallic Acid Removal from Water by MIEX Resin Based on Response Surface Methodology. Processes. 8 (3), 1, 2020.

24. ABBOUD R., POPA R., SOUZA-EGIPSY V., GIOMETTI C.S., TOLLAKSEN S., MOSHER J.J., FINDLAY R.H., NEALSON K.H. Low-temperature growth of Shewanella oneidensis MR-1. Appl. Environ. Microbiol. 71 (2), 811, 2005.

25. LEMAIRE O.N., HONORE F.A., TEMPEL S., FORTIER E.M., LEIMKUEHLER S., MEJEAN V., IOBBI-NIVOL C. Shewanella decolorationis LDS1 Chromate Resistance. Appl. Environ. Microbiol. 85 (18), e00777, 2019.

26. GUO J., ZHOU J., WANG D., TIAN C., WANG P., UDDIN M.S. A novel moderately halophilic bacterium for decolorizing azo dye under high salt condition. Biodegradation. 19 (1), 15, 2008.

27. KECK A., RAU J., REEMTSMA T., MATTES R., STOLZ A., KLEIN J. Identification of quinoide redox mediators that are formed during the degradation of naphthalene2-sulfonate by Sphingomonas xenophaga BN6. Appl. Environ. Microbiol. 68 (9), 4341, 2002.

28. HARTSHORNE R.S., REARDON C.L., ROSS D., NUESTER J., CLARKE T.A., GATES A.J., MILLS P.C., FREDRICKSON J.K., ZACHARA J.M., SHI L. Characterization of an electron conduit between bacteria and the extracellular environment. Proc. Natl. Acad. Sci. U S A. 106 (52), $22169,2009$.

29. LELLIS B., FÁVARO-POLONIO C.Z., PAMPHILE J.A., POLONIO J.C. Effects of textile dyes on health and the environment and bioremediation potential of living organisms. Biotechnol. Res. Innov. 3 (2), 275, 2019. 


\section{Supplementary Material}

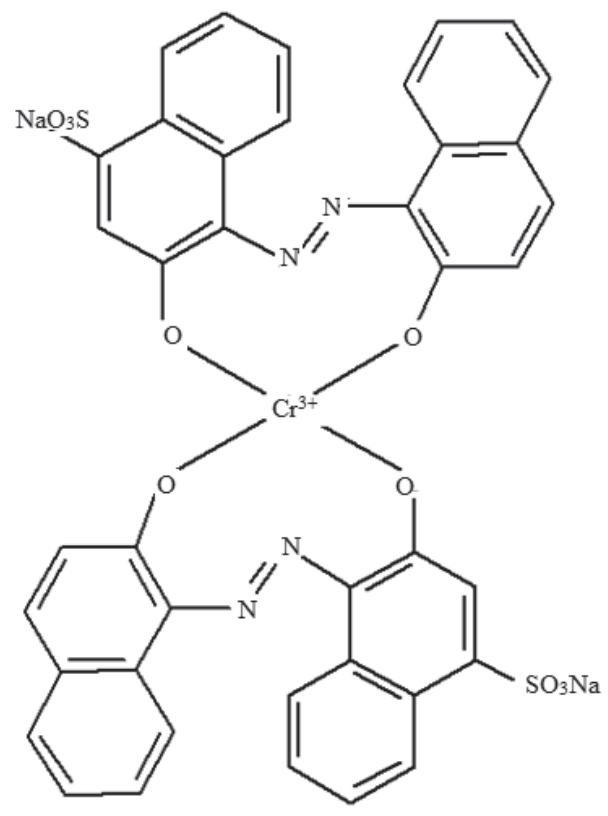

Fig. S1. Molecular structure of Acid Blue 193.

The molecular formula of this dye is $\mathrm{C}_{40} \mathrm{H}_{22} \mathrm{CrN}_{4} \mathrm{Na}_{2} \mathrm{O}_{10} \mathrm{~S}_{2}$, and its maximum absorption wavelength is at $575 \mathrm{~nm}$.<smiles></smiles>

Fig. S2. Chemical structure of neutral red. Its molecular formula is $\mathrm{C}_{15} \mathrm{H}_{17} \mathrm{CIN}_{4}$

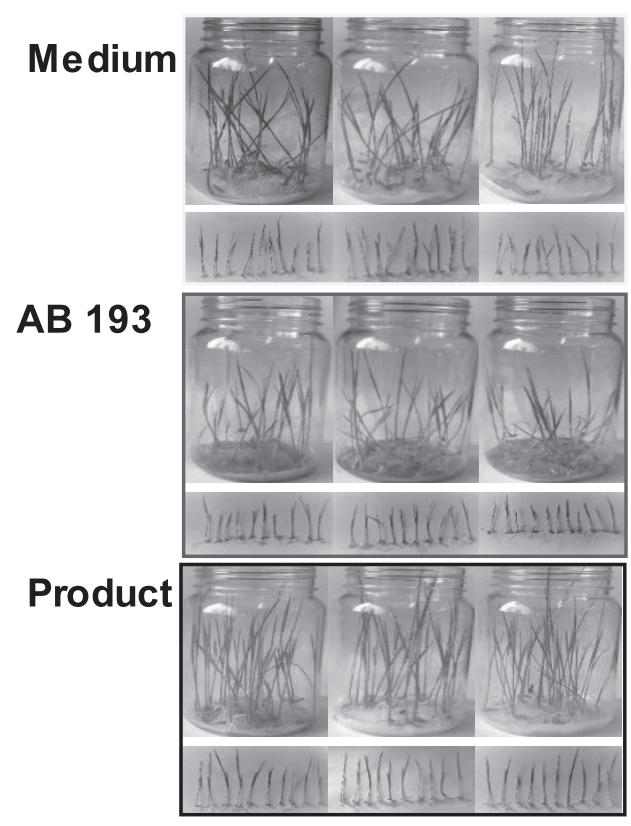

a)

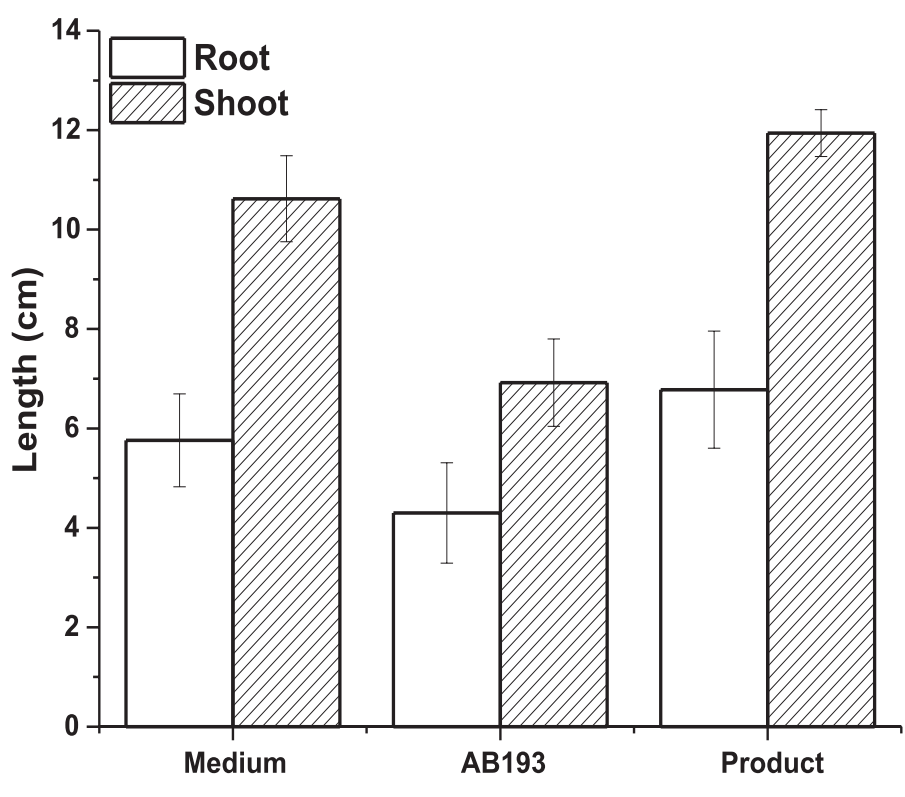

b)

Fig. S3. The effects of AB 193 and its decolorization products to a) the growth of rice seedlings and b) the length of the root and shoot of the rice plant. 
Table S1 Model summary statistics for the response analyzed

\begin{tabular}{|c|c|c|c|c|c|}
\hline Source & $\begin{array}{c}\text { Sequential } \\
\mathrm{p} \text {-value }\end{array}$ & $\begin{array}{c}\text { Lack of Fit } \\
\mathrm{p} \text {-value }\end{array}$ & $\begin{array}{c}\text { Adjusted R- } \\
\left.\text { Squared (Adj-R }{ }^{2}\right)\end{array}$ & $\begin{array}{c}\text { Predicted R- } \\
\left.\text { Squared (Pre-R }{ }^{2}\right)\end{array}$ & Remarks \\
\hline Linear & $<0.0001$ & 0.153 & 0.6455 & 0.5521 & \\
\hline 2FI & 0.8861 & 0.1081 & 0.5797 & 0.2316 & Suggested \\
\hline Quadratic & 0.001 & 0.4644 & 0.8443 & 0.6331 & Aliased \\
\hline Cubic & 0.4821 & 0.3648 & 0.8501 & -0.8623 & \\
\hline
\end{tabular}

Table S2 Experimental and predicted values for model confirmation experiments conducted at optimum conditions.

\begin{tabular}{|c|c|c|c|c|c|c|c|}
\hline Number & $\mathrm{pH}$ & $\begin{array}{c}\text { Temperature } \\
\left({ }^{\circ} \mathrm{C}\right)\end{array}$ & $\begin{array}{c}\text { NR dosage } \\
(\mu \mathrm{M})\end{array}$ & $\begin{array}{c}\text { Initial AB 193 } \\
\text { concentration } \\
(\mathrm{mg} / \mathrm{L})\end{array}$ & $\begin{array}{c}\text { Predicted } \\
\text { decolorization } \\
\text { efficiency }(\%)\end{array}$ & $\begin{array}{c}\text { Observed } \\
\text { decolorization } \\
\text { efficiency }(\%)\end{array}$ & Desirability \\
\hline 1 & 7 & 27.5 & 7.9 & 95.1 & 97.5 & 91.3 & 1.0 \\
\hline 2 & 7 & 31.2 & 2.8 & 52.4 & 99.9 & 93.4 & 1.0 \\
\hline 3 & 7 & 28.1 & 7.9 & 80.0 & 96.2 & 90.1 & 1.0 \\
\hline 4 & 7 & 26.2 & 4.2 & 50.4 & 99.9 & 94.5 & 1.0 \\
\hline 5 & 7 & 30.1 & 3.5 & 52.7 & 99.9 & 95.9 & $1.0($ selected $)$ \\
\hline
\end{tabular}

